\title{
MODEL PEMBELAJARAN ANAK BERKEBUTUHAN KHUSUS DALAM SETTING PENDIDIKAN INKLUSI
}

\author{
Norma Yunaini \\ FKIP, Universitas Muhammadiyah Pringsewu Lampung \\ normayunaini@umpri.ac.id
}

\begin{abstract}
This study aims to namely the design of appropriate learning models for children with special needs in inclusive classes. This research is important to understands the learning of special needs students according to their needs and characteristics, to achieve optimal learning. The type of research that researchers do is field research (Field Research) based on qualitative research. This study resulted in three conclusions, namely: 1) classical learning model. 2) contextual learning model. 3) direct learning model. The process includes concrete learning media that are easy to find and easy to use.
\end{abstract}

Keywords: learning, special needed, inclusive education

\section{PENDAHULUAN}

Pemerataan pendidikan bagi Anak Berkebutuhan Khusus (ABK) saat ini telah diupayakan oleh pemerintah. Salah satunya adalah dengan adanya pendidikan inklusi. Pendidikan inklusi merupakan pendidikan yang menggabungkan antara anak norma dengana anak ABK. Pendidikan inklusi dipandang sebagai salah satu upaya yang efektif dalam mengembangkan keterampilan sosial bagi ABK maupun anak norma agar dapat hidup bersamaan, saling memahami dan menerima.

Berdasarkan pada edaran surat Dirjen Dikdasmen Depdiknas No.380/C.C6/MN/2003 tiap jenjang pendidikan di setiap kabupaten dan kota diwajibkan menyelenggarakan pendidikan inklusi. Pada pelaksanaan pendidikan inklusi, sekolah menyiapkan suatu layanan khusus bagi ABK dan program pembelajaran yang sesuai dengan karakteristik dan kebutuhan tiap individu. Hal demikian memberikan kesempatan yang seluas-luasnya bagi ABK yang memiliki hambatan fisik, emosional, mental untuk memperoleh pendidikan yang bermutu sesuai dengan kebutuhan dan kemampuannya, serta mewujudkan pendidikan yang menghargai keanekaragaman, tidak diskriminatif bagi semua peserta didik.

Sekolah penyelenggara pendidikan inklusi menurut Stainback (dalam Ifa Arifah. 2014:3) adalah sekolah yang menampung semua murid di kelas yang sama 


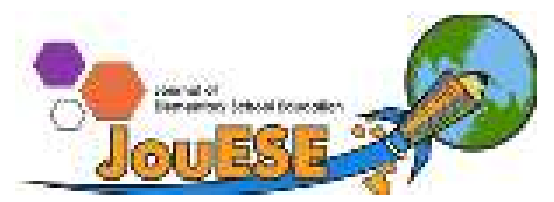

dengan layanan pendidikan yang disesuaikan dengan kemampuan dan kebutuhan anak. Kebutuhan tiap murid di sekolah inklusi tentu tidak semua sama. Oleh karena itu, kebebasan bagi guru untuk dapat mengembangkan ide-ide maupun pemikiran yang kreatif sangat dibutuhkan. Tuntutan bagi guru di sekolah inklusi jauh lebih besar dibanding sekolah umum. Guru di sekolah inklusi dituntut untuk mengembangkan seluruh kemampuannya dalam pemanfaatan perkembangan ilmu pengetahuan dan teknologi yang akan disajikan kepada peserta didik. Akan tetapi, masih banyak pelaksanaan pendidikan di sekolah inklusi yang belum sesuai dengan apa yang telah ditetapkan oleh Pemerintah.

Hambatan yang dialami ABK gangguan fisik, emosional, mental dan intelektual menyebabkan mereka kesulitan dalam bersosialisasi dengan orang lain sehingga kebutuhan dalam pembelajaran yang diterapkan tidak dapat disamakan dengan anak normal pada umumnya. Model pembelajaran yang dapat digunakan dalam kelas inklusi memerlukan pertimbangan berdasarkan karakteristik dari anak tersebut. Selain itu memerlukan potensi guru yang berpengalaman di bidang keilmuan untuk menangani ABK.

Anak berkebutuhan khusus adalah anak-anak yang dalam proses tumbuh kembangnya mengalami gangguan dan hambatan secara bermakna (significantly) dari kriteria normal dalam karakteristik : mental/intelektual (yang gifted maupun yang retarded), sensorik, neuromotor atau fisik, perilaku sosial, kemampuan berkomunikasi/kesulitan belajar, berpenyakit kronis, atau gabungan dari dua atau lebih karakteristik tersebut; dan karena gangguan dan hambatan tersebut diperlukan modifikasi layanan pendidikan yang disebut pendidikan khusus (special education) (PERMENDIKNAS No.70, 2009). Keunikan dan keberagaman ABK tidak menghalangi untuk mendapat akses pendidikan yang bermutu. Hal tersebut dapat diperoleh melalui pendidikan inklusi dengan pendidik, tenaga kependidikan sekolah yang memahami dan memiliki ketrampilan dalam pendidikan inklusi, serta berkomitmen dalam memberikan pelayanan pendidikan bermutu bagi ABK.

Pendidikan inklusif adalah penerimaan anak-anak yang memiliki hambatan ke dalam kurikulum, lingkungan, interaksi sosial, dan konsep diri (visimisi) sekolah. Pada sekolah inklusif, setiap anak sesuai dengan kebutuhan 
khususnya, semua diusahakan dapat dilayani secara optimal dengan melakukan berbagai modifikasi dan atau penyesuaian mulai dari kurikulum, sarana prasarana, tenaga pendidik dan kependidikan, sistem pembelajaran sampai sistem penilaiannya (Anggraini, R.L, 2014).

Pembelajaran bagi ABK haruslah yang akomodatif, sehingga dapat memfasilitasi perbedaan antara anak ABK dengan siswa regular. Materi pembelajaran dirancang sefleksibel mungkin agar dapat dengan mudah tersampaikan kepada siswa ABK. Materi pembelajaran bagi siswa berkebutuhan khusus juga bukan hanya pada bidang akademik saja, akan tetapi guru juga perlu memberikan pengetahuan yang fungsional dalam kehidupannya. Metode pembelajaran yang dilaksanakan di kelas hendaknya juga bervariatif, agar siswa tidak bosan. Media pembelajaran yang dapat digunakan bagi siswa adalah media yang sesuai dengan karakteristiknya, yakni media yang konkret dan mudah digunakan.

Salah satu sekolah yang ditunjuk untuk menyelenggarakan pembelajaran inklusi adalah SD Taman Muda Yogyakarta. Setiap sekolah baik sekolah regular (inklusi) maupun sekolah luar biasa (SLB) memiliki model pembelajaran, inovasi dan kreatifitas yang berbeda-beda dalam menerapkan pembelajaran kepada siswanya. Model pembelajaran memiliki pengaruh besar bagi kesuksesan belajar pembelajaran, karena jika kerangka konseptual pembelajaran matang dibentuk dan dilaksanakan, maka akan menciptakan pembelajaran yang efektif di sekolah. model pembelajaran yang baik dan sesuai dengan kondisi siswa, akan memberikan kenyamanan baik bagi pendidik, siswa dan lingkungan pembelajaran.

Agar pendidikan inklusif terjadi dalam proses pembelajaran di kelas, perlu ada beberapa pra-kondisi, sekurang-kurangnya (1) ada pemahaman konsep pendidikan inklusi yang benar, (2) ada penerimaan tentang pendidikan inklusi oleh warga sebagai strategi untuk memberikan akses pendidikan yang lebih baik bagiABK, (3) guru memiliki kompetensi menangani dan mengajar ABK, (4) tersedia sumber-sumber dukungan di sekitar sekolah, dan (5) mendapat dukungan warga sekolah dan masyarakat.

Berdasarkan hasil wawancara dengan guru kelas 4 SD Taman Muda Yogyakarta, diperoleh informasi bahwa guru sering mengalami kesulitan dalam 


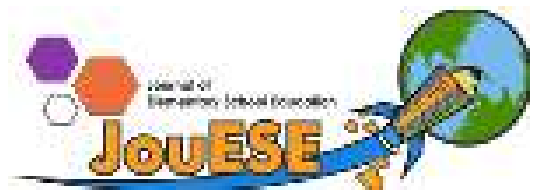

menyampaikan materi yang diajarkan. Pembelajaran kurang optimal dikarenakan guru harus menjelaskan beberapa kali dalam satu materi. Selain itu kurang berpengalamannya guru pendamping, serta kualifikasi guru yang belum mendukung dalam penanganan ABK di sekolah inklusi (hasil wawancara guru kelas). Topik ini penting diangkat untuk melihat desain pembelajaran dan model pembelajaran yang diterapkan oleh pendidik atau guru dalam menyampaikan pembelajaran, pada lembaga pendidikan inklusi SD Taman Muda Yogyakarta.

\section{METODE PENELITIAN}

Penelitian dilaksanakan di SD Taman Muda Yogyakarta. Sekolah tersebut sudah menyelenggarakan pendidikan inklusif sekurang-kurangnya 7 tahun. Kondisi tersebut diharapkan akan memberikan gambaran dan dapat terpenuhinya kebutuhan penggalian data yang diperlukan berkaitan dengan penyusunan desain pembelajaran yang inklusif. Jenis penilitian yang peneliti lakukan ini adalah penelitian lapangan (Field Research) dengan berdasarkan penelitian kualitatif. Penelitian ini adalah kajian tentang desain dan model pembelajaran kepada anak inklusi. Penelitian ini mendasar dan mendalam serta berorientasi pada proses sehingga menghasilkan kesimpulan yang signifikan.

Penelitian ini termasuk penelitian kualitatif diskriptif, yaitu prosedur penelitian yang menghasilkan data deskriptif berupa kata-kata tertulis atau lisan dari orang-orang dan pelaku yang diamati, diarahkan pada latar belakang individu secara utuh tanpa mengisolasikan individu dan organisasi dalam variable atau hipotesis, tetapi memandangnya sebagai bagian dari suatu keutuhan. Teknik pengumpulan data yang digunakan yaitu metode wawancara, metode observasi, dan metode studi dokumen.

\section{HASIL DAN PEMBAHASAN}

Berdasarkan hasil observasi yang dilakukan di SD Taman Muda diketahui bahwa guru sudah melakukan pembelajaran adaptif bagi anak berkesulitan belajar yaitu pembelajaran yang menyesuaikan dengan kondisi siswa. Artinya, pembelajaran tersebut menyesuaikan dengan kondisi peserta didik itu sendiri, yang tentunya penyesuaian tersebut berkaitan dengan metode strategi, materi, alat atau media pembelajaran, dan lingkungan belajar. Model 


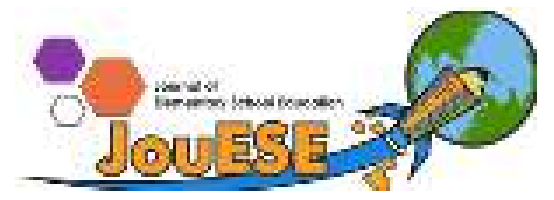

pembelajaran yang dilakukan oleh guru kelas 4 dan 5 yaitu model klasikal. Siswa normal dan berkebutuhan khusus mengikuti pembelajaran dalam satu kelas. Model kedua yaitu model pembelajaran individual. Siswa yang mengalami kesulitan belajar atau berkebutuhan khusus mendapatkan tambahan jam belajar yang biasanya dilaksanakan setelah jam pelajaran selesai. Selain itu, di SD Taman Muda terdapat guru pendamping yang bertugas mendampingi guru kelas ketika di dalam pembelajaran guru kelas tersebut mengalaami kesulitan.

Strategi guru dalam mengajar kelas inklusi yaitu guru menyampaikan materi pelajaran yang diselingi dengan sedikit permainan. Hal ini dikarenakan siswa kelas inklusi cenderung memiliki tingkat konsentrasi yang di bawah ratarata. Teknik evaluasi yang dilakukan oleh guru kelas dengan cara mengurangi kompetensi bagi kelas inklusi serta menurunkan tingkat materi bagi siswa. Adapun strategi atau metode yang biasa dilakukan guru seperti tanya jawab, diskusi yang dikemas menggunakan teknik-teknik yang dimiliki oleh guru kelas itu sendiri dengan menyesuaikan kondisi peserta didiknya serta penataan tempat duduk yang dibuat melingkar dan mengelompok.

Siswa kelas inklusi memperoleh penilaian melalui dua buah buku laporan siswa yaitu laporan nilai (raport) dan buku laporan perkembangan siswa. Selain berkordinasi dengan guru pendamping pihak SD Taman Muda juga mengadakan pertemuan rutin dengan para wali siswa kelas inklusi. Tujuannya agar pihak orang tua juga ikut membimbing dan mengarahkan perkembangan putra-putrinya. Berdasarkan hasil wawancara dengan orang tua siswa berkebutuhan khusus diketahui bahwa mereka sangat menyayangi dan memperhatikan perkembangan putra putrinya selama di sekolah. Hal demikian juga diutarakan oleh kepala sekolah, guru kelas dan guru pendamping bahwa orang tua sangat perhatian pada putra putrinnya. Hal inilah yang memang seharusnya dilakukan para orang tua yang dikaruniai anak spesial. Selain itu orang tua bekerjasama dengan pihak sekolah tentang perkembangan anak.

Berdasarkan hasil penelitian kendala yang dialami SD Taman Muda dalam penerapan pendidikan inklusi yaitu sebagai berikut: (1) latar belakang pendidikan para guru yang masih belum sesuai kualifikasi; (2) kurikulum bagi siswa yang normal dan siswa yang spesial terutama dalam hal standar penilaian 
atau evaluasi; (3) perhatian dari pemerintah masih kurang terkait pelaksaan pendidikan inklusi baik dari segi sarana prasarana dan biaya; (4) sarana dan prasarana yang masih terbatas untuk sekolah yang melaksanakan pendidikan inklusi; dan (5) pelatihan atau workshop terkait pendidikan inklusi bagi guru yang berlatar belakang pendidikan diluar psikologi atau PLB masih kurang. Temuan tersebut hendaknya ditindaklajuti karena setiap warga negara mempunyai hak yang sama untuk memperoleh pendidikan yang bermutu.

Komponen-komponen dalam pelaksanaan pendidikan inklusif terdiri dari perencanaan pelaksanaan pendidikan inklusif yang meliputi modifikasi kurikulum, tenaga pendidik, peserta didik, sarana dan prasarana, keuanganatau dana, lingkungan, alternatif penempatan; pelaksanaan sistem pendidikan inklusif yang meliputi merencanakan kegiatan belajar mengajar, melaksanakan kegiatan belajar mengajar, membina hubungan antar pribadi; evaluasi pelaksanaan pendidikan inklusif.

Berdasarkan hasil wawancara, guru kelas sering melaporkan perasaan tidak siap untuk pendidikan inklusif. Peneliti mengidentifikasi beberapa isu penting, yaitu menjelaskan bagaimana menangani siswa, mempertimbangkan tantangan pengembangan profesional guru yang muncul dari studi proyek. Pelajaran penting berfokus pada pengembangan profesional guru dalam pembentukan pendekatan kurikuler baru untuk pembahasan pendidikan inklusif.

Guru pendamping (shadow teacher) memiliki tugas yaitu membantu anak atau peserta didik untuk; 1) tetap fokus pada pelajaran, 2) berpartisipasi secara tepat di kelas, 3) memberitahu guru jika anak tidak memahami materi, 4) bersikap positif pada tugas-tugas baru dan control diri, 5) berbagi kepentingan khusus dengan anak-anak lain, 6) merespon dengan tepat terhadap teman-teman dalam situasi sosial, 7) memperoleh informasi dan ketrampilan baru, 8) meningkatkan sosialisasi dengan teman sebaya, 9) mandiri dalam kegiatan kelas. Shadow teacher hendaknya dapat berkolaborasi dengan orang tua, guru, staf sekolah dan profesional lain dalam mendampingi masing-masing anak berkebutuhan khusus.

Hal ini juga menunjukan bahwa orang tua dari anak berkebutuhan khusus mulai memilih menyekolahkan anak-anaknya pada sekolah formal yang umum 
daripada sekolah luar biasa atau sekolah khusus untuk anak berkebutuhan khusus seperti yang terjadi di SD Taman Muda.

\section{SIMPULAN}

Berdasarkan hasil observasi, dokumentasi dan wawancara terhadap guru dan siswa. pada hasil penerapan ditemukan model pembelajaran kontekstual lebih relevan untuk pembelajaran ABK di kelas inklusif. Model pembelajaran ini memberikan pengalaman nyata pada siswa inklusi yang sulit untuk berfikir abstrak. Penerapan model pembelajaran kontekstual terhadap siswa inklusi secara praktek tidak sepenuhnya memberikan dampak peningkatan hasil belajar siswa, apabila tidak dilakukan secara terus-menerus.

\section{DAFTAR PUSTAKA}

Ainscow, M. (2005). Understanding the development of inclusive education system. Journal of Research in Educational Psychology, 3, 5-20.

Anjaryati, Fibriana. 2011. Pendidikan Inklusi Dalam Pembelajaran Beyondcenters And Circle Times (Bcct) Di Paud InklusiAhsanu Amala Yogyakarta. Tesis . Yogyakarta: UIN Kalijaga.

Anggraini, R.L. Proses Pembelajaran Inklusi untuk Anak Bekebutuhan Khusus kelas V SD Negeri Giwangan, Yogyakarta. 2014.

Nugroho, A. 2016. Pendidikan special untuk yang spesial. Prosiding Seminar Nasional Menjadi Guru Inspirator "Kenali Dan Kembangkan Kemampuan Intelegensi Generasi Emas Untuk Indonesia Emas. Purwokerto: UMP.

Asriningtyas, Rosmalina. 2015. Sikap Guru Terhadap Pelaksanaan Pendidikan Inklusif di SD Inklusif Se-Kabupaten Purbalingga Skripsi. UNY.

Ifa Arifah, 2014, Pelaksanaan Pembelajaran Bagi Siswa Tunagrahita, (Yogyakarta: Universitas negeri Yogyakarta).

Kwon, H. (2005). Inclusion in South Korea: The current situation and future directions. International Journal of Disability, Development and Education(52), 59-68.

Nur'aeni, dkk. 2014. Model Program Pembelajaran Individual Untuk Peserta Didik Dengan Kesulitan Belajar Melalui Pelatihan Terapi Gerak Bagi 


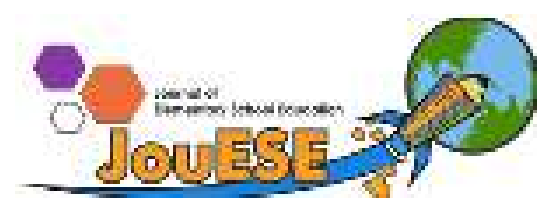

Shadow Teacher di SD Inklusi. Prosiding SnaPP 2014 Sosial, Ekonomi, dan Humaniora. ISSN 2089-3590/EISSN 2303-2472

Muleong, Laxy J.(2000).Metodologi Penelitian Kualitatif, Bandung: Rosadakarya. Permerintah Dirjen Dikdasmen Depdiknas No.380/C.C6/MN/2003 perihal pendidikan inklusi

Prawiradilaga, D. S. (2007). Prinsip Desain Pembelajaran. Jakaarta: Prenada Media Grup. Sagala, S. (2010). Konsep dan Makna Pembelajaran. Bandung: Alfabeta.

Prastiyono, (2013) Implementasi Kebijakan Pendidikan Inklusif (Studi di Sekolah Galuh Handayani Surabaya). DIA, Jurnal Administrasi Publik Juni 2013, Vol.11, No.1, Hal. 117-128. Pascasarjana-Untag Surabaya

Sternberg, L., \& Taylor, R. L. (1986). Exceptional Children: Integrating Research and Teaching. New York: Springer-Verlag.

Sunardi. (1997). Kecenderungan dalam Pendidikan Luar Biasa. Jakarta: Didjed Dikti. Suparno. (2001). Desain Pembelajaran untuk Guru TK Inklusif. Cakrawala Pendidikan, $X X X$.

Sunaryo. 2009. Manajemen Pendidikan Inklusif (Konsep, Kebijakan, dan Implementasinya dalam Perspektif Pendidikan Luar Biasa). Makalah. Bandung: UPI.

UNESCO. (2003). Overcoming Exclusion through Inclusive Approaches in Education. A Challenge and vision. Conceotual Papaer.

UNESCO, \& PLAN-Indonesia. (2006). Pernyataan Salamanca dan Kerangka Aksi tentang Pendidikan Khusus tahun 1994. Kompendium Perjanjian, Hukum, dan Peraturan Menjamin Semua Anak Memperoleh Kesamaa Hak untuk Kualitas Pendidikan dalam Cara Inklusif. Jakarta: UNESCO Office. 